\title{
Palliative care for non-cancer patients - Case reports of systemic lupus erythematosus
}

\author{
F. Akama1', K. Mikami1', K. Kimoto1, N. Watanabe1, T. Iga1, \\ K. Yamamoto', H. Matsumoto'. \\ ${ }^{1}$ Tokai University School of Medicine, psychiatry, Isehara, \\ Japan.
}

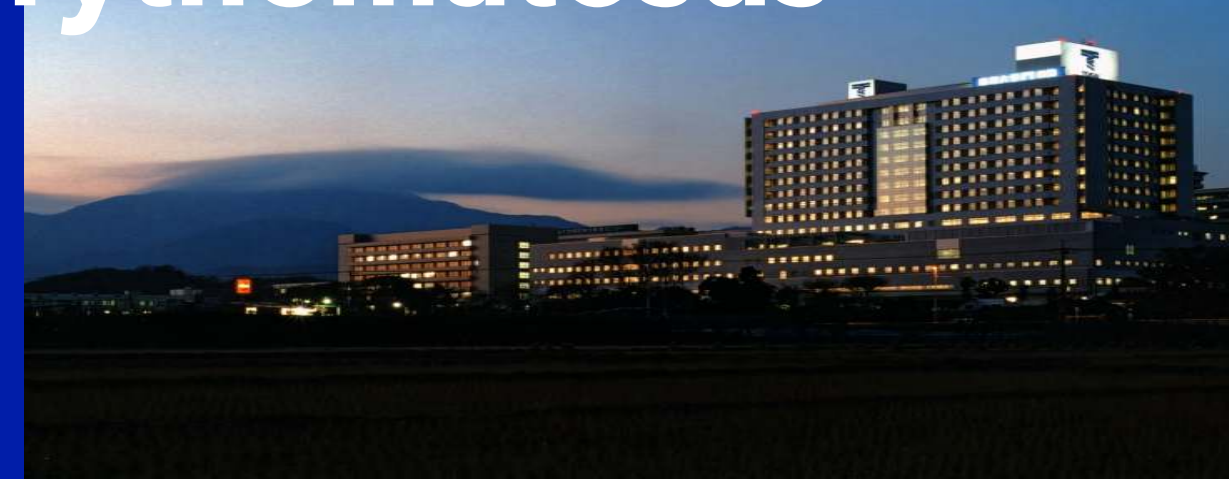

\section{Introduction}

The Global Atlas of Palliative Care at the End of Life, published by the World Health Organization and Worldwide Palliative Care Alliance in 2014, reported that worldwide, one-third of patients who required palliative care had terminal cancer, while two-thirds had a non-cancer disease ${ }^{1)}$. Although patients with systemic lupus erythematosus (SLE) have been cases of fatal complications, there are no reports of palliative care for SLE. We investigated clinical characteristics of palliative care patients with non-cancer disease and presented two cases of SLE.

\section{Methods}

Eight hundred and fifty-one patients who requested palliative care during the 5-year investigation period (from January 1, 2013 to December 31, 2017) at our hospital, data from 26 patients with non-cancer diseases who were diagnosed with diseases such as causative diseases and psychiatric disorders, were retrospectively analyzed.

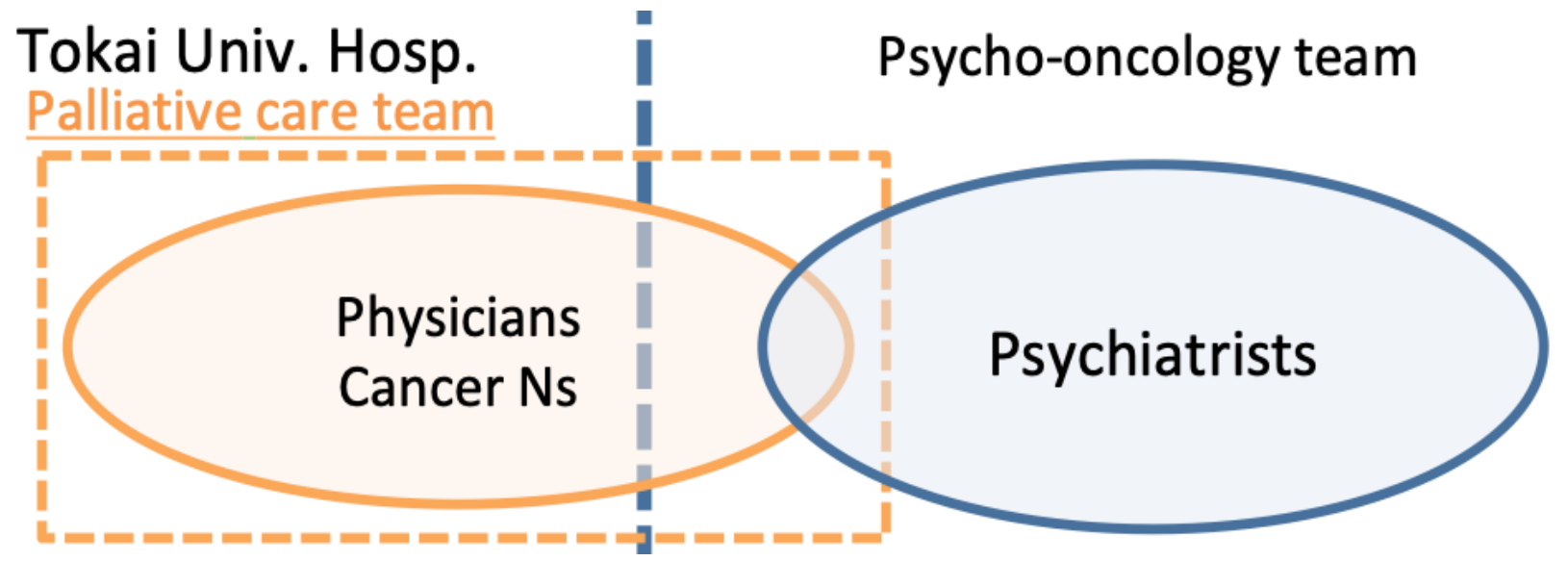

Results

The physical disorders of the 26 patients (mean age, 65.2 years; 14 men and 12 women) were amyotrophic lateral sclerosis, dilated cardiomyopathy, chronic heart failure, SLE, etc (Table 1). The two patients were SLE, one had coexistent pulmonary alveolar hemorrhage and presented with dyspnea and psychological anxiety, and the other had coexistent skin ulcers and presented with pain, insomnia, and psychological anxiety.

\begin{tabular}{|c|c|c|c|}
\hline physical disease & reason of consultation & outcome & $\begin{array}{c}\text { psychiatric diagnosis by } \\
\text { DSM-IV-TR }\end{array}$ \\
\hline 1 M 57 polyarteritis nodosa & pain control & $\begin{array}{l}\text { discharged (other } \\
\text { hospital) }\end{array}$ & sleep disorder \\
\hline $2 \mathrm{M} \quad 80$ dilated cardiomyopathy, heart failure & e dyspnea,eating difficulty & died & sleep disorder \\
\hline $3 \mathrm{M} 72$ arteriosclerosis obliterans (ASO) & pain control & discharged (home) & no diagnosis \\
\hline $4 \mathrm{M} 72 \mathrm{ASO}$ & pain control & discharged (home) & no diagnosis \\
\hline $\begin{array}{ll}5 \mathrm{M} & \begin{array}{l}\text { perforations of the gastrointestinal } \\
\text { tract }\end{array}\end{array}$ & pain control & died & delirium \\
\hline $6 \mathrm{M} 39 \mathrm{ASO}$ & pain control & $\begin{array}{l}\text { discharged (other } \\
\text { hospital) }\end{array}$ & $\begin{array}{l}\text { adjustment disorder, } \\
\text { personarity disorder }\end{array}$ \\
\hline $7 \mathrm{M} 82$ otomycosis in chronic otitis media & pain control & discharged (home) & adjustment disorder \\
\hline $8 \mathrm{M} 84$ chronic heat failure & dyspnea & died & adjustment disorder \\
\hline 9 M 48 alcoholic liver cirrhosis & anxiety, depression & died & adjustment disorder \\
\hline $10 \mathrm{M} 41$ chronic pyodermas & pain control & discharged (home) & adjustment disorder \\
\hline $11 \mathrm{M} 43$ chronic pyodermas & pain control, panic attack & discharged (home) & panic disorder \\
\hline $12 \mathrm{M} 73$ amyotrophic lateral sclerosis (ALS) & anxiety, insomnia & died & sleep disorder \\
\hline $13 \mathrm{M} 72 \mathrm{ASO}$ & pain control & discharged (home) & sleep disorder \\
\hline $14 \mathrm{M} 85 \mathrm{COPD}$, heat failure & dyspnea, insomnia & died & sleep disorder \\
\hline 15 F 81 critical limblschemia (CLI) & pain control & $\begin{array}{l}\text { discharged (other } \\
\text { hospital) }\end{array}$ & no diagnosis \\
\hline $16 \quad F \quad 38$ SLE & pain control & died & adjustment disorder \\
\hline $17 \mathrm{~F} 87$ chronic heat failure & dyspnea & died & no diagnosis \\
\hline $18 \mathrm{~F} \quad 55 \mathrm{ASO}$ & pain control & died & no diagnosis \\
\hline $19 \mathrm{~F} 55 \mathrm{ASO}$ & pain control & other & no diagnosis \\
\hline $\begin{array}{lcc} & \text { interstitial pneumonia, pulmonary } \\
20 & \mathrm{~F} & 79 \text { hypertension }\end{array}$ & dyssnea & died & no diagnosis \\
\hline $21 \mathrm{~F} \quad 62 \mathrm{SLE}$, takotsubo cardiomyopathy & dyspnea, pain control & died & no diagnosis \\
\hline $22 \quad F \quad 47$ aplastic anemia & $\begin{array}{l}\text { dyspnea, attentional } \\
\text { disturbance }\end{array}$ & discharged (home) & delirium \\
\hline $23 \mathrm{~F} 90$ chronic heat failure & dyspnea, pain control & died & dementia \\
\hline $\begin{array}{ll} & \text { chronic heat failure, interstitial } \\
24 & F \quad 85 \text { pneumonia }\end{array}$ & dyspnea & died & delirium \\
\hline $25 \mathrm{~F} \quad 47$ aplastic anemia & $\begin{array}{l}\text { eating difficulty,rbrain } \\
\text { dysfunction }\end{array}$ & $\begin{array}{l}\text { discharged (other } \\
\text { hospital) }\end{array}$ & organic psychosis \\
\hline $26 \mathrm{M} 77$ burn & $\begin{array}{l}\text { pain control,, attentional } \\
\text { disturbance }\end{array}$ & $\begin{array}{l}\text { discharged (other } \\
\text { hospicel) }\end{array}$ & delirium \\
\hline
\end{tabular}

Case 1. 38 years old, female.

At the age of 11, she was diagnosed with SLE and complicated by lupus nephritis, skin ulcer, and systemic sclerosis. And, she was also diagnosed with adjustment disorder at the age of 25 because of anxiety and depressive mood by pain of chronic skin ulcers.

At the age of 38 , she had coexistent pulmonary alveolar hemorrhage and presented with dyspnea and psychological anxiety, so she was admitted to our hospital in an emergency. Because of more terrible pain of skin ulcers, dyspnea, psychological anxiety, and insomnia, she was treated by the palliative care team. The pain and dyspnea were controlled by opioids and the psychological anxiety and insomnia by anxiolytics and hypnotics. Finally, she succumbed to exacerbating pulmonary alveolar hemorrhage with no discomfort.

Case 2. 62 years old, female.

At the age of 17, she was diagnosed with SLE and complicated by lupus nephritis and takotsubo cardiomyopathy. She had no prior psychiatric disease and no steroid psychosis.

At the age of 62, her foot skin ulcers and heat failure got worse and she presented with dyspnea and pain, and psychological anxiety. So she was admitted to our hospital in an emergency, and treated by the palliative care team. The pain and dyspnea were controlled by opioids and the psychological anxiety by psychotherapy. Finally, she succumbed to multiple organ failure with no discomfort.

\section{Conclusion}

There were still few requests for palliative care in non-cancer patients in Japan. SLE patients experience high physical and psychological suffering from more comorbidities like lupus nephritis, skin ulcer, CNS lupus and suffering from side effects of steroids $^{2}$. At the end-of-life of SLE patients, sepsis/bacteria, acute respiratory failure, and acute lower respiratory conditions contribute most frequently to the ultimate death, and so SLE patients are suffering from pain, dyspnea, delirium, anorexia, anxiety ${ }^{2,3)}$. In our two cases, SLE patients were suffering from many complications and the pain, dyspnea, anxiety.

A liaison from the department of psychiatry is often requested in SLE cases due to psychiatric symptoms caused by the disease or as side effects of steroid therapy, but the results of the present study showed that it may be necessary to provide palliative care as early as possible to SLE patients with serious complications and other non-cancer disease.

This study has no fund and $\mathrm{COI}$.

\section{References}

1) WHO.WPCA: Global Atlas of Palliative Care at the End of Life. 2) J. Cho et al. Palliative and end-of-life care in rheumatology:

High symptom prevalence and unmet needs. Seminars in Arthritis and Rheumatism. 49, 2019.

3) Kang SC et al. Characteristics of comorbidities and costs

among patients who died from systemic lupus eryhematosus in

Taiwan. Arch Med Sci. 4, 2012. 